\title{
HIGH TECH, LOW TECH, RIGHT TECH
}

\author{
Valentino J. Stella \\ University Distinguished Professor of \\ Pharmaceutical Chemistry \\ University of Kansas
}

\begin{abstract}
Around 1980, I helped discover the new antiseizure drug, fosphenytoin. It took almost 16 years for this drug to undergo clinical trials and to be approved by the FDA. Because of our naivete at the time, we did not file for worldwide patent protection. Only patent protection in the United States was granted, and the compound was licensed to a company at a low royalty rate. Also, the licensing agreement did not have milestone payments and a due diligence clause, which contributed to the delay in reaching the market place, i.e. the University could not place any pressure on the companies involved to "move things along." Thus the health benefits to society were delayed and the financial benefits to the University were less than they could have been.
\end{abstract}

The University of Kansas and other universities have become more savvy at technology transfer and licensing. State and State/private economic development units such as KTEC (Kansas Technology Enterprise Corporation) have helped support applied research allowing promising university-based research concepts to be advanced to "commercial grade" quality. Thus technologies can be moved beyond concept to potential commercial reality, increasing their value and hopefully the economic impact to the State. Also, because of our past experiences, we have learned what our intellectual property is worth and have developed the expertise to negotiate more favorable agreements.

We have helped launch three new companies over the last seven years. The bases for the companies have been technologies developed in the Center for Drug Delivery Research at the Higuchi Biosciences Center. It is our hope that these three companies will prosper and contribute significantly to the Kansas economy by providing high paying, technologybased jobs. With each new company we launch, we become smarter at optimizing the return to the State and the University. One of the goals of KTEC and the Centers of Excellence can be best defined by the cycle shown on the following page. 


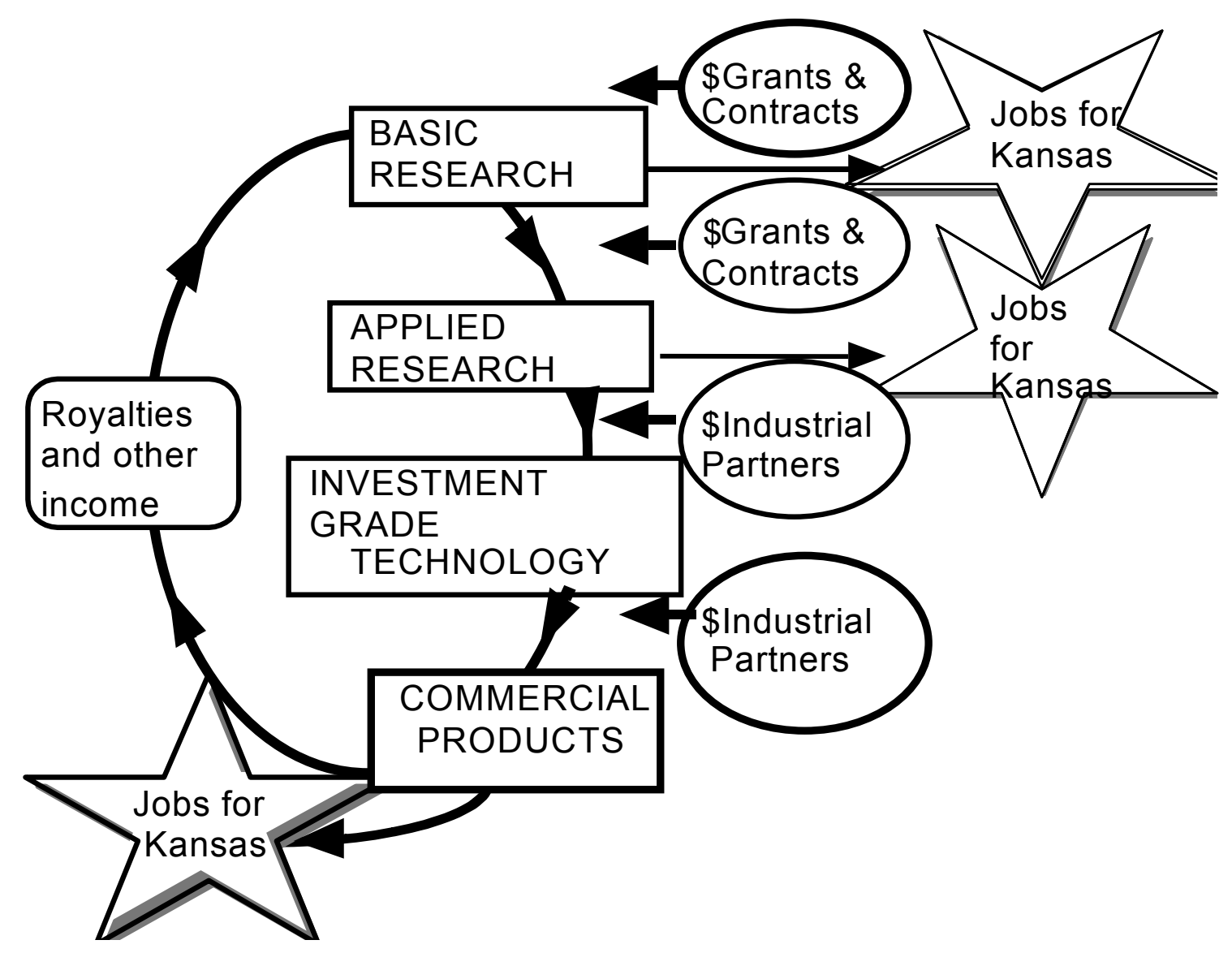

To be successful, the University, and each of these companies, had to protect their intellectual property by filing patents in a timely manner. This leads to a bit of a dilemma, that can be described as "Publish AND Perish." I would like to quote verbatim from an "Opinion" article I wrote in the Lawrence Journal World in 1993.

"Publish AND perish. What heresy! Traditionally, universities have existed to generate and disseminate knowledge. They encourage publication through the tenure, promotion and merit salary processes, in which quantity and quality of publications plays a major role; thus the often-quoted cliché "publish OR perish." However, in some fields or areas of research there are occasional, valid reasons to delay publication of information on novel technologies until patents or copyrights can be filed.

The state, nation and society might be the losers if information about promising new technologies developed at universities is made public prior to receiving patent or copyright protection. Unprotected technology is unlikely to ever be developed and used to the benefit of society. It's a simple case of economics. Let me explain by using examples in my own field, pharmaceutical sciences. 
To develop a new drug and obtain approval by the FDA, a company must invest a minimum of around $\$ 250-500$ million, and the process takes 8 to 12 years. The drug must achieve annual sales of more than $\$ 250$ 500 million/year over the five to nine years remaining in the 20-year patent life. This allows the company to recoup its investment, continue its product line through research and development of other drug entities, and cover the cost of products that fail to reach the market. In the unlikely event that a company were to take unprotected technology through the regulatory process to gain FDA approval, generic companies would be free to produce the product at a fraction of the cost and risk. They would not have to spend the $\$ 250-500$ million in R\&D and regulatory costs. The sponsoring company would not cover its costs and would lose any economic benefit even though they might be first with the technology.

It just does not make economic sense to invest in a new drug or technology unless a strong worldwide patent protects it. As a result, few companies or investors will negotiate with inventors for rights to a new pharmaceutical technology if it is unprotected.

While patent protection is essential for commercialization, its real value lies in the fact that it enables development of a new drug or technology, which might save lives or enhance the quality of life. The drug's therapeutic benefits might allow individuals to return to the work force, thus lowering health care costs and reducing the direct and indirect financial burden to society. Additionally, university-based research often focuses on cures and treatments for more obscure diseases that may not be big money makers but may be commercialized under the "orphan" drug act.

There are also financial benefits to the university and society for a protected technology. First, the university is in a much stronger position to negotiate a favorable agreement with potential developers of the new technology. The university and state will profit by the creation of a revenue stream that can be put to creative uses in research and scholarship or general enhancement of the university mission. The developer profits, thus creating new jobs at the research, sales and manufacturing levels. And finally, as part of the negotiations for rights to the technology, leverage can be put on the developer for some or all of the technology to be developed locally, thus creating jobs in the geographical area.

There are some negatives to patenting. The cost of filing and defending a worldwide patent could easily rise above $\$ 125,000$, with additional annual maintenance fees required. This is above and beyond the cost of the research itself, which in the case of many technologies can 
be very high. Such costs are not trivial, thus discouraging universities and inventors unless they have a sure winner. And when can you be certain that you have a sure winner?

Delaying publication until patents are filed conflicts with one of the principle aims of academic institutions, which is the sharing of new knowledge in a timely manner. Pressure to publish from the tenure and promotion standpoint and excitement about the discovery of new knowledge often lead faculty inventors to share their findings immediately rather than waiting to file patents or copyrights. The inventor may gain in prestige through early publication, but society loses when promising new technology is never developed because it is not protected prior to publication. How would you feel if you knew that someone discovered a potential cure for cancer or AIDS, but it could not benefit society because lack of patent protection made it too economically risky to develop?"

As more of us are asked to balance basic with applied research we need to be aware of the need to protect our intellectual property in a timely manner. Universities must continue to find ways to support the protection of intellectual property while not losing sight of their greater goal of generating and disseminating new knowledge. 